\title{
Scheimpflug Records without Distortion - A Mythos?
}

\author{
H.-J. Huebscher ${ }^{\mathrm{a}} \quad$ W. Fink ${ }^{\mathrm{b}} \quad$ D. Steinbrück ${ }^{\mathrm{a}} \quad$ T. Seiler $^{\mathrm{c}}$ \\ aAugenklinik im Klinikum Buch, Berlin, bInstitut für theoretische Physik, Universität \\ Tübingen, und ${ }^{\mathrm{c}}$ Augenklinik im Universitätsklinikum CGC, TU Dresden, Deutschland
}

\section{Key Words}

Scheimpflug imaging $\cdot$ Corneal radii .

Ray tracing $\cdot$ Opacity

\begin{abstract}
The Scheimpflug principle was recommended as allowing distortion-free imaging; however, a detailed analysis reveals geometrical errors as well as distortions arising from absorption of light along the optical pathway. Correction formulas and factors will be presented and applied to the biometry of the eye.
\end{abstract}

The Scheimpflug camera was designed to create a perfect $1: 1$ sectional image of the eye along the visual axis. Although the Scheimpflug principle delivers the most reproducible images to date, a more exact examination yields geometrical distortions. Few papers so far have investigated such distortions and found a different quality of data [1-5].

Based on the definitions depicted in figure 1, the Scheimpflug image size is dependent on the imaging ratio in the y-direction:

$$
y^{\prime}=\frac{f}{f-\frac{1}{\sqrt{2}} y} y, \quad x^{\prime}=\frac{f}{f-\frac{1}{\sqrt{2}} y} x
$$

where $f$ is the focal length of the imaging lens. Figure 2 shows in an exaggerated manner, how a rectangular grid is distorted by the Scheimpflug imaging process. For the Topcon SL-45 camera these distortions are usually small; however, in some cases they must not be neglected. With the applied equipment [6], an estimation of the distortion factors using records of precise and calibrated grids yielded a variation of $1.5 \mu \mathrm{m}$ in the y-direction and of $0.5 \mu \mathrm{m}$ in the $\mathrm{x}$-direction.

\begin{tabular}{ll}
\hline KARGER & (1) 1999 S. Karger AG, Basel \\
Fax +41 61 306 1234-3747/99/0312-0134\$17.50/0 \\
$\begin{array}{l}\text { E-Mail karger@karger.ch } \\
\text { www.karger.com }\end{array}$ & $\begin{array}{l}\text { Accessible online at: } \\
\text { http://BioMedNet.com/karger }\end{array}$
\end{tabular}

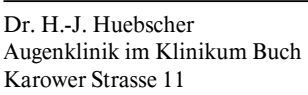


Fig. 1. The Scheimpflug imaging.

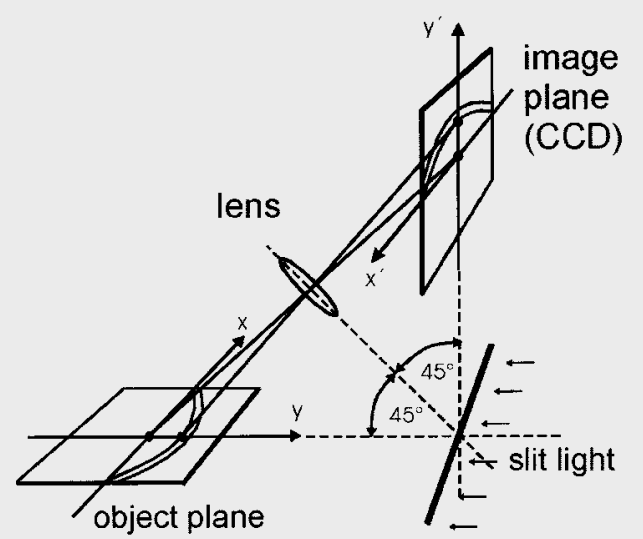

\begin{abstract}
.
\end{abstract}
Fig. 2. Demonstration of the distortion by the Scheimpflug imaging of a rectangular grid.
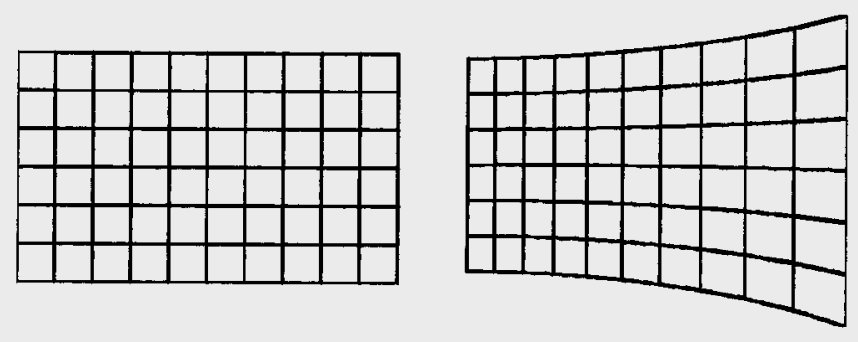

Fig. 3. Estimated corneal structure coordinates from a digital Scheimpflug image: anterior structure data (a), posterior structure data (b) and the correct data of the posterior structure (c).

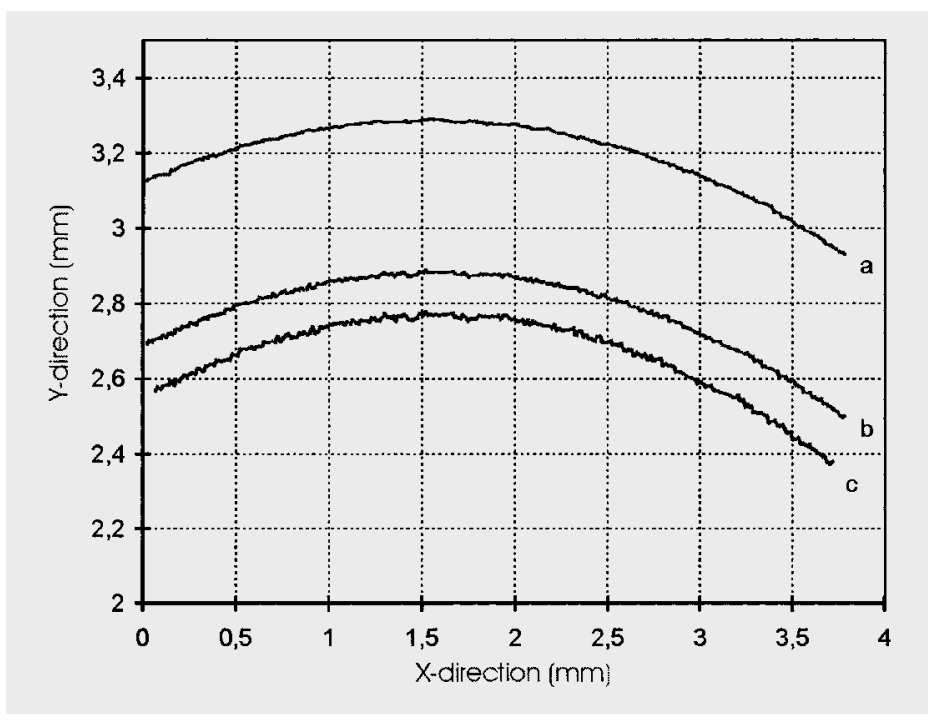


Fig. 4. A normal Scheimpflug videography with the region of interest.

Fig. 5. Enlargement of the region of interest from figure 4 .
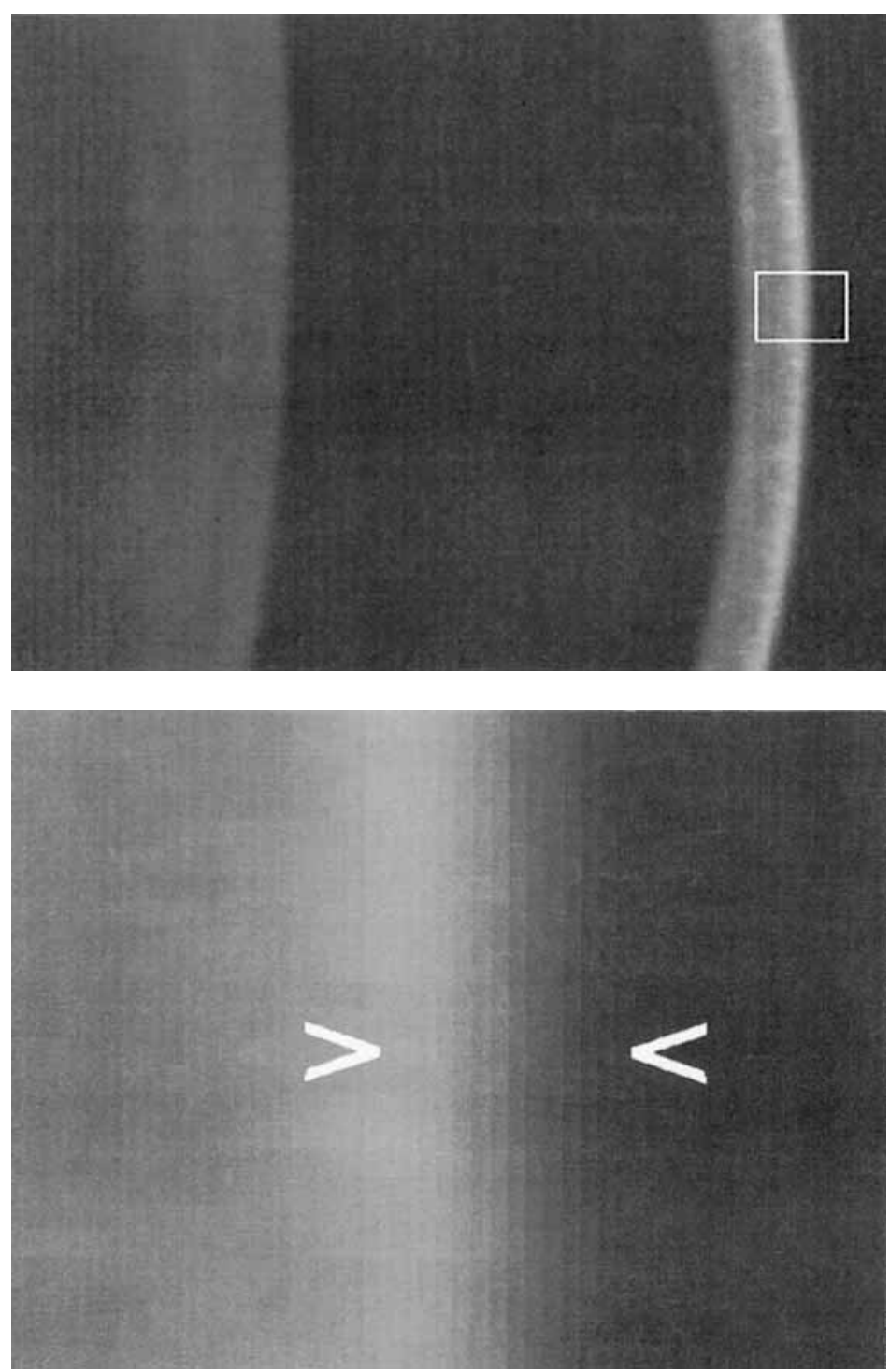

In addition, when imaging the eye the curvature of the cornea plays an important role. Based on the results of Ohlsen et al. [7] on pachometry for Scheimpflug imaging, the thickness of the cornea could be determined exactly only in the center of the cornea from directly obtained image data.
Digital Scheimpflug records of the cornea provide structure coordinates for the corneal surfaces when using a subpixel algorithm for evaluation [8] (fig. 3. curves a and b). The pictures shown in figures 4 and 5 clarify the difficulty of an exact positioning of the structure borders. Due to the continual blurredness of 
Fig. 6. A graph for the optical correction algorithm.

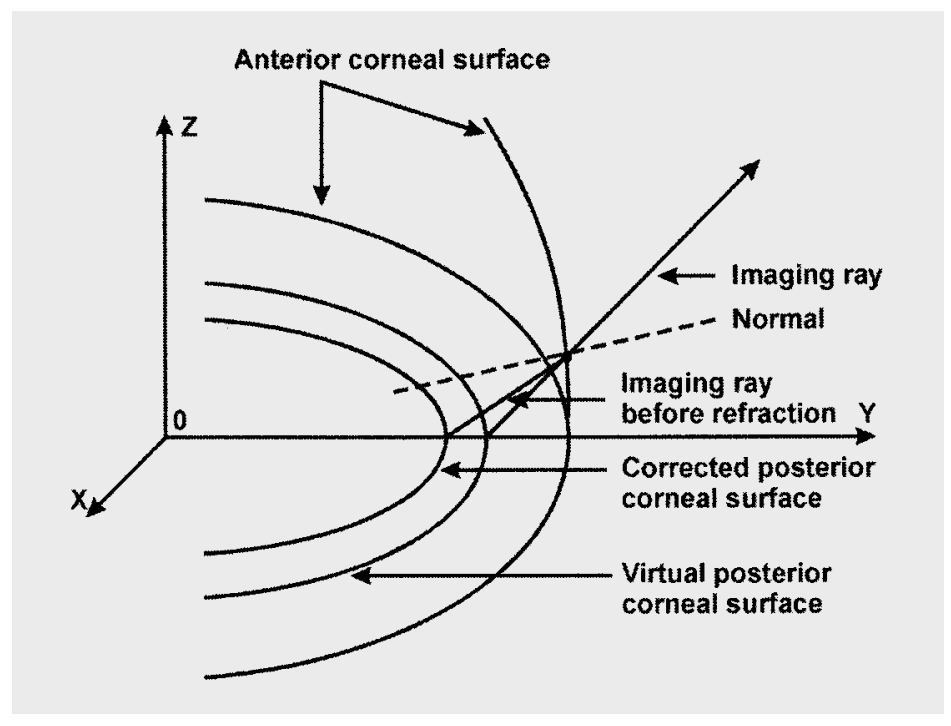

Fig. 7. A comparison of Scheimpflug images: above, an image with a normal cornea; below, the model M4 with a homogeneous opacity which is about the normal opacity of the cornea.

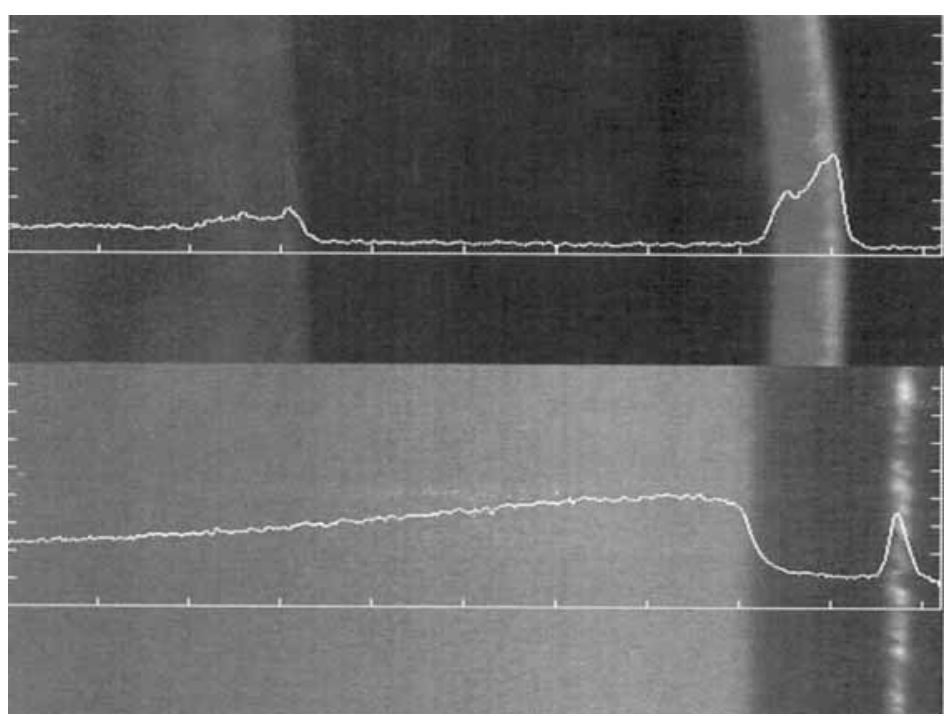

the image even an interactive determination of the borders seems to be difficult if not impossible (fig. 5).

In order to obtain correct coordinates of the posterior surface of the cornea, the refraction taking place at the anterior surface has to be taken into account (fig. 6). In a first step,

Scheimpflug Records without Distortion - A Mythos? the intersection points of the parallel rays (which image the posterior surface) with the anterior surface have to be calculated using the anterior curvature including the local distances from the intersection points of the parallel rays, which image the anterior surface. In the next step, the application of Snellius' law 
Fig. 8. A comparison of Scheimpflug images: above, an image of a lens with a nucleus cataract; below, the model M8 with a homogeneous opacity with about the concentration of a nucleus cataract.

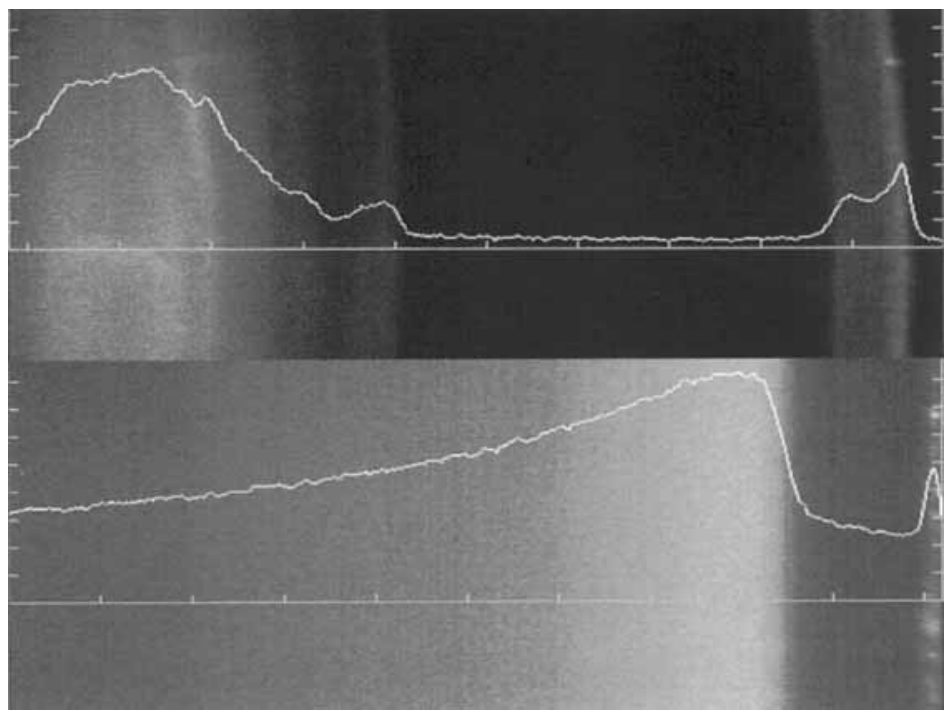

Fig. 9. Scheimpflug images of a cuvette with a glass plate in it: above, the cuvette is empty: below, it is filled with a suspension of a homogeneous opacity.

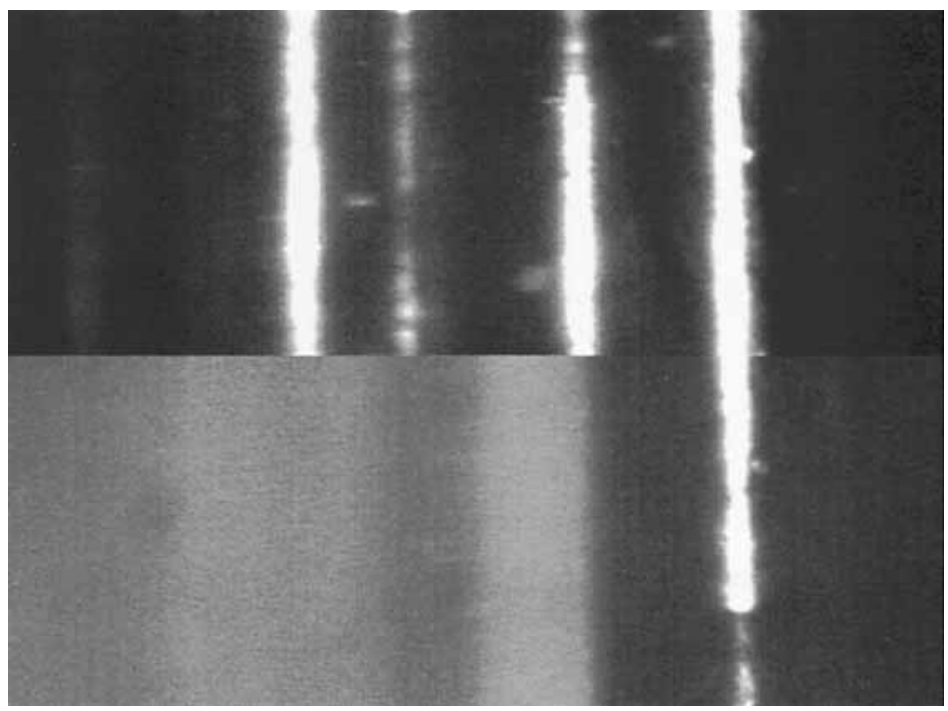

requires the normals to the surface in the intersection points. However, it is important to know that after the refraction at the anterior surface the light rays are still located in the plane defined by the incoming rays and the normals of the corneal surface. The thus corrected coordinates of the posterior surface can be calculated as the intersections of the slit plane and the rays, which underwent refraction at the anterior surface.

Applying this algorithm to all 512 coordinates of the posterior surface in our pictures yielded a shrinking effect in the vertical direction. Therefore, the radius of curvature of the 
posterior surface of the cornea shown in figure 3 decreased from $r_{i}=6.48 \mathrm{~mm}$ to $r_{i c}=$ $5.84 \mathrm{~mm}$.

Once the real curvatures are known for both corneal surfaces, we are able to determine also the real curvature of the lens (anterior surface) and the real anterior chamber depth.

Even the densitometric evaluation of Scheimpflug records is plagued by distortions due to light absorption and scattering. This problem is demonstrated by models consisting of two cuvettes containing homogeneous dispersions of milk in water. One of the models (M4 in fig. 7) represents an opacity comparable to the normal cornea whereas the second is more opaque (M8 in fig. 8) equivalent to a cataractous lens. The longer the optical pathway through the opaque media, the less light can be detected. At a penetration depth of $0.5 \mathrm{~mm}$ in M4, a reduction of light of $5 \%$ takes place. At
$2 \mathrm{~mm}$ penetration in M8 (cataract suspension) the light intensity decreases by $25 \%$. In general, due to scattering and absorption the light penetrating is reduced according to an exponential law similar to Lambert-Beer's law.

The importance of such distortions is illustrated in figure 9 presenting two records of a cuvette with a glass plate in it. In the upper part, the cuvette is empty; in the lower part, it has been filled with a liquid of homogeneous opacity. In the lower part of figure 9 the distance between wall and glass plate appears to be shorter compared to the upper part (without opacity). In addition, even the glass plate appears to be opaque, although in reality it is not.

We have presented general distortions that may play a role in standard Scheimpflug imaging. These distortions also occur during clinical slitlamp inspection and, therefore, even clinicians should be aware of them.

\section{References}

1 Jäger W: Tiefenmessung der menschlichen Vorderkammer mit planparallelen Platten (Zusatzgerät zur Spaltlampe). Graefes Arch Ophthalmol 1952;153:120-131.

2 Richards DW, Russel SR, Anderson DR: A method for improved biometry of the anterior chamber with a Scheimpflug technique. Invest Ophthalmol Vis Sci 1988;29:18261835.
3 Hachicha A, Simon S, Samson J, Hanna K: The use of gray-level information and fitting techniques for precise measurement of corneal curvature and thickness. Comput Graphics Image Process 1989; 7 : 131-164.

4 Kampfer T, Wegener A, Dragomirescu V, Hockwin O: Improved biometry of the anterior eye segment. Ophthalmic Res 1989;21: 239-248.

5 Olbert T: Optical problems of anterior chamber depth biometry by Scheimpflug photography. Ophthalmic Res 1991;23:342-347.
6 Huebscher H-J, Schmidt H: On-line Scheimpflug imaging and its potential for in vivo examination of cornea and lens. Ophthalmic Res 1994; 26(suppl 1):33-38.

7 Ohlsen T, Nielsen CB, Ehlers N: On the optical measurement of corneal thickness. I. Optical principle and sources of error. Acta Ophthalmol 1980;58:760-766.

8 Huebscher H-J, Gent U, Möller DE, Seiler T: Comparison of pixel and subpixel accuracy for biometry in digital Scheimpflug imaging. Invest Ophthalmol Vis Sci 1997;38:S1093. 